\title{
Echogenicity of the substantia nigra region in Parkinson's disease
}

\author{
Ecogenicidade da substância negra na doença de Parkinson \\ Edson Bor-Seng-Shu, Kelson James Almeida, Daniel Ciampi de Andrade, Erich Talamoni Fonoff, \\ Manoel Jacobsen Teixeira, Egberto Reis Barbosa
}

Hospital das Clínicas, University of São Paulo School of Medicine (FMUSP), São Paulo, Brazil.

Correspondence: Edson Bor-Seng-Shu; Divisão de Cirurgia Neurológica, Hospital das Clínicas, USP; Avenida Dr. Eneas de Carvalho Aguiar 255; $05403-000$

São Paulo SP - Brasil; E-mail: edsonshu@hotmail.com

Conflict of interest: There is no conflict of interest to declare.

Received 04 September 2011; Received in final form 14 September 2011; Accepted 21 September 2011

Idiopathic Parkinson's disease (PD) is a progressive neurodegenerative disorder which affects 1 to $2 \%$ of the population over 60 years. The differential diagnosis between PD and atypical Parkinsonian syndromes is usually difficult in the medical practice, mainly in the beginning of clinical manifestation. Modern neuroimaging techniques, such as PET and SPECT, have proved to be useful in the clinical scenario, although expensive and inaccessible ${ }^{1}$.

Transcranial sonography (TCS) of the brain has recently emerged as a novel diagnostic test for the evaluation of movement disorders ${ }^{1,2}$. The authors report a patient with PD in whom TCS disclosed hyperechogenicity of the substantia nigra (SN) region; the significance of this finding ( $\mathrm{SNH}$ ) in the clinical practice was discussed.

\section{CASE REPORT}

A 54-year-old female had a 16-year history of PD which followed a characteristic course with gradually worsening symptoms. Hand tremor at rest began initially on the left side and, after 3 years, both sides were affected. Current neurological examination revealed an asymmetric tremor, bradykinesia and muscle rigidity; there were posture and balance dysfunctions, and reduction of automatic movements. Results of brain CT and MRI were normal. TCS of the brain parenchyma disclosed a SN echogenic area greater than $0.20 \mathrm{~cm}^{2}$, bilaterally, fulfilling the criteria for SNH (Figure). Written informed consent was obtained from the patient.

\section{DISCUSSION}

SNH, visualized by TCS, has been considered a biological marker for PD. This ultrasound sign is found in the majority of PD patients (>90\%) and has been demonstrated to be associated with functional impairment of the nigrostriatal dopaminergic system ${ }^{1-3}$.

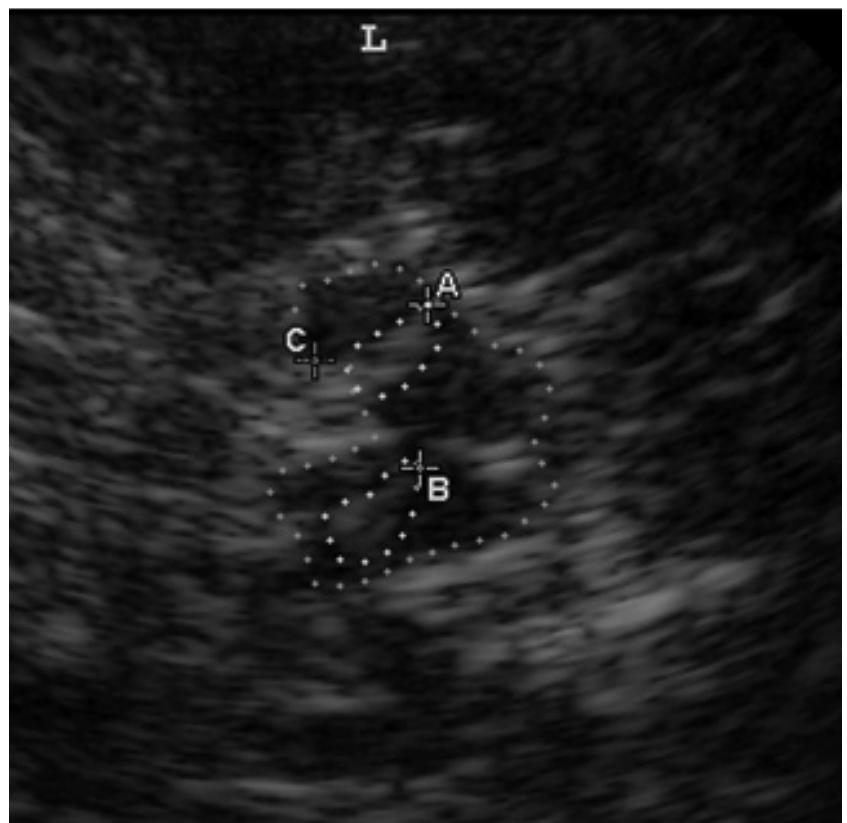

Figure. Transcranial sonographic images of the midbrain. The butterfly-shaped midbrain and the substantia nigra region hyperechogenicity were encircled.

Animal and human postmortem analyses have attributed increased iron content in the SN as a cause for the hyperechogenicity ${ }^{1,2}$. It is not known, however, whether increased SN iron levels may cause oxidative stress and secondary neuronal damage or whether SN degenerative process leads to increased iron content in the SN region ${ }^{3}$.

$\mathrm{SNH}$ is less frequently encountered in essential tremor, vascular parkinsonism, multiple system atrophy and progressive supranuclear palsy while this echo feature occurs in most PD patients ${ }^{1,4,5}$. SNH can be found in a minority of healthy subjects (10\%) and they are more likely to develop extrapyramidal signs and symptoms following administration of neuroleptic ${ }^{1,2,5}$.

Some factors limit the usefulness of TCS, such as its dependence on the operator experience and the lack of temporal acoustic windows (about $10 \%$ of patients) ${ }^{1}$. No correlation 
was found between the degree of SNH and the severity of dopaminergic innervations impairment ${ }^{4}$; moreover, $\mathrm{SNH}$ seems not to change during the course of $\mathrm{PD}$, so that the progression of PD cannot be monitored by TCS 3 .

Future longitudinal studies must address if $\mathrm{SNH}$ can help to identify PD patients at preclinical stages mainly if considered in conjunction with other nonmotor signs of PD, such as depression, olfactory dysfunction, neuropsychological deficits and idiopathic REM sleep behavior disorder ${ }^{5}$. If this idea is true, PD could be identified before manifestation of typical signs and symptoms, allowing development of neuroprotective therapies ${ }^{1-5}$.

\title{
References
}

1. Berg D, Godau J, Walter U. Transcranial sonography in movement disorders. Lancet Neurol 2008;7:1044-1055.

2. Bor-Seng-Shu E, Fonoff ET, Barbosa ER, Teixeira MJ. Substantia nigra hyperechogenicity in Parkinson's disease. Acta Neurochir (Wien) 2010;152:2085-2087.

3. Berg D, Merz B, Reiners K, Naumann M, Becker G. Five-year followup study of hyperechogenicity of the substantia nigra in Parkinson's disease. Mov Disord 2005;20:383-385.
4.

Barsottini OG, Felício AC, de Carvalho Aguiar P, et al. Heterozygous exon 3 deletion in the Parkin gene in a patient with clinical and radiological MSA-C phenotype. Clin Neurol Neurosurg 2011;113:404-406.

5. Berg D, Jabs B, Merschdorf U, Beckmann H, Becker G. Echogenicity of substantia nigra determined by transcranial ultrasound correlates with severity of parkinsonian symptoms induced by neuroleptic therapy. Biol Psychiatry 2001;50:463-467.

\section{Vasculitic neuropathy following influenza seasonal vaccination}

\author{
Neuropatia por vasculite após vacinação para influenza sazonal \\ Paulo J. Lorenzoni, Rosana H. Scola, Cláudia S. Kamoi Kay, Eustáquio de Queiroz, Juliana Cardoso, \\ Lineu C. Werneck
}

Neuromuscular Disorder Service, Neurology Division, Internal Medicine Department, Hospital de Clínicas da Universidade Federal do Paraná (UFPR), Curitiba PR, Brazil.

Correspondence: Rosana Herminia Scola; Serviço de Doenças Neuromusculares; Hospital de Clínicas da UFPR; Rua General Carneiro 181 / $3^{\circ}$ andar; 80060-900 Curitiba PR - Brasil. ; E-mail:scola@hc.ufpr.br

Conflict of interest: There is no conflict of interest to declare.

Received 02 August 2011; Received in final form 02 September 2011; Accepted 12 September 2011

Influenza seasonal vaccination is widely performed and clearly justified on public healthy grounds. However, neurological complications have been reported following influenza vaccinations ${ }^{1}$.

We describe a case of small vessel vasculitis with involvement of skin and peripheral nerves after influenza seasonal vaccination.

\section{CASE REPORT}

A 24-year-old woman presented 21 days after influenza seasonal vaccination arthralgias on ankles and knees associated with skin rash in the legs. Four days after initial symptoms, she developed parestesia in her fingers, toes and lateral region of right leg associated to weakness in left hand and right foot.

On physical examination, she had purpuric cutaneous rash on both ankles and lower limbs (Fig A and B). Neurological examination revealed weakness in left hand and right foot, and diffuse reduction in deep tendon reflexes. Pain, pinprick and light touch were impaired distally in the arms and legs, more pronounced in region of left ulnar nerve and right peroneal nerve.

Laboratory tests, as well as serological tests, were normal. Electrophysiological study showed an asymmetrical sensorymotor axonal neuropathy consistent with multiplex mononeuropathy. Skin biopsy showed leucocytoclastic vasculitic (Fig C). Sural nerve biopsy showed inflammatory perivascular infiltration in the small vessel in epineurium and a reduction 